Article

\title{
A Mapping Approach for Efficient CFD Simulation of Low-Speed Large-Bore Marine Engine with Pre-Chamber and Dual-Fuel Operation
}

\author{
Ying Ye ${ }^{1} \mathbb{D}$, Zongyu Yue ${ }^{1, *}$, Hu Wang ${ }^{1}$, Haifeng Liu ${ }^{1}{ }^{(}$, , Chaohui $\mathrm{Wu}^{2}$ and Mingfa Yao ${ }^{1} \mathbb{(}$ \\ 1 State Key Laboratory of Engines, Tianjin University, Tianjin 300072, China; ye_y@tju.edu.cn (Y.Y.); \\ wang_hu@tju.edu.cn (H.W.); haifengliu@tju.edu.cn (H.L.); y_mingfa@tju.edu.cn (M.Y.) \\ 2 China Shipbuilding Power Engineering Institute Co., Ltd., Shanghai 200120, China; wch@cspi.net.cn \\ * Correspondence: zongyuyue@tju.edu.cn; Tel.: +86-2740-6832
}

Citation: Ye, Y.; Yue, Z.; Wang, H.; Liu, H.; Wu, C.; Yao, M. A Mapping Approach for Efficient CFD

Simulation of Low-Speed Large-Bore Marine Engine with Pre-Chamber and Dual-Fuel Operation. Energies 2021, 14, 6126. https://doi.org/ $10.3390 /$ en14196126

Academic Editor: Pinaki Pal

Received: 20 August 2021

Accepted: 22 September 2021

Published: 26 September 2021

Publisher's Note: MDPI stays neutral with regard to jurisdictional claims in published maps and institutional affiliations.

Copyright: (C) 2021 by the authors Licensee MDPI, Basel, Switzerland. This article is an open access article distributed under the terms and conditions of the Creative Commons Attribution (CC BY) license (https:// creativecommons.org/licenses/by/ $4.0 /)$.

\begin{abstract}
AbstractA natural-gas-diesel dual-fuel marine engine with a pre-chamber is a promising solution for ocean transportation to meet the International Maritime Organization (IMO) emission regulations. This engine system employs a pre-chamber with direct injection of diesel to ignite premixed natural gas due to its higher ignition energy, which can enable lower lean limit and higher thermal efficiency. The dual-fuel pre-chamber marine engine presents complex multi-regime combustion characteristics in- and outside the pre-chamber, thus posing challenges in its numerical simulation in a cost-effective manner. Therefore, this paper presents a three-dimensional modeling study for the multi-regime combustion in a large-bore two-stroke marine dual-fuel engine, proposing a novel mapping approach, which couples the well-stirred reactor (WSR) model with the G-equation model to achieve high computational accuracy and efficiency simultaneously. In-depth analysis is performed using representative exothermic reaction (RXR) analysis and premixed turbulent combustion fundamentals to better understand the combustion process and to provide guidance in the selection of mapping timing. The results show that the use of mapping to switch from the WSR to the G-equation model can effectively reduce the runtime significantly by $71.5 \%$, meanwhile maintaining similar accuracies in predictions of in-cylinder pressure traces, HRR and NOx emissions, compared to using WSR all along. Additionally, the choice of mapping timing based on several parameters is preliminarily discussed.
\end{abstract}

Keywords: marine engine; CFD; dual fuel; pre-chamber; multi-regime combustion

\section{Introduction}

In recent decades, the emission regulations of the International Maritime Organization (IMO) are becoming drastically stricter [1,2], posing challenges for marine engines to work in a more environmentally friendly manner and more efficiently. For example, the third-stage standard (IMO Tier III) has been implemented since 2016 of which a limit on oxynitride $\left(\mathrm{NO}_{x}\right)$ emission in the emission control areas (ECAs) corresponds to an $80 \%$ reduction in IMO Tier I standard [3], and the global fuel sulfur limit of $0.5 \%$ also came into force in 2020. Meanwhile, in order to contribute to the climate change mitigation, IMO announced its initial strategy on greenhouse gas (GHG) reduction targeting at $>50 \%$ reduction in GHG emissions in 2050 compared to 2008 [4]. Therefore, the maritime sector is in urgent need of clean fuels with a low carbon footprint alternative to the heavy oil fuel (HOF) currently used in marine engines. Liquefied natural gas (LNG) has been a promising solution, since it provides great potentials for the reduction in $\mathrm{NO}_{x}$ emissions and has near-zero sulfur content [5-7]. In addition, the $\mathrm{H} / \mathrm{C}$ mass ratio of $\mathrm{NG}$ is much higher compared to conventional fossil fuels, leading to an approximately 20-25\% reduction in $\mathrm{CO}_{2}$ emissions during combustion compared to HOF [8]. 
LNG is employed on low-speed marine engines usually with a premixed lean combustion strategy to achieve higher thermal efficiency and better emission performance. However, unstable ignition events and slow flame propagation at fuel-lean condition often result in high cycle-to-cycle variability, thus limiting the high-efficiency operating range [9]. A pre-chamber ignition system can be used to improve the ignition stability and accelerate the combustion process under lean conditions. In general, there are two kinds of pre-chamber systems, namely, the active pre-chamber and passive pre-chamber [10]. A passive pre-chamber does not have dedicated fuel injection system, and the fuel comes from the main chamber through the channel orifice. An active pre-chamber, on the other hand, has fuel directly injected into the pre-chamber and, thus, can form a richer mixture than in the main chamber, allowing a lower lean limit for potentially higher efficiency compared to a passive pre-chamber. The mixture inside the pre-chamber can be ignited by a spark ignition (SI) system usually seen on light-/heavy-duty engines for road transportation. Alternatively, a diesel-type liquid fuel (usually diesel or HOF) can be injected into the pre-chamber and auto-ignite under the high temperature and pressure condition, serving as an ignition source for the premixed NG, i.e., dual-fuel pre-chamber engine. This application is usually seen on the large-bore marine engine to provide an intensive ignition energy for stable ignition and combustion. [11,12]. Regardless of the ignition method, flame jet or hot jet [13] from the pre-chamber combustion emit into the main chamber and initiate the main combustion event.

Nowadays, numerical simulation has become an essential tool in engine research and development $(R \& D)$ process. The simulation method for a pre-chamber with SI can be basically considered similar to that for a typical SI engine, which consists of modeling for the spark ignition process and premixed flame propagation. The former can be modeled using spark ignition models [14-16] with varying accuracies, and the latter can be efficiently modeled using a premixed flamelet model, e.g., the G-equation model [17]. Wei et al. [18] reported a study applying optical diagnostics and numerical simulation on spark-ignited premixed flame structure evolution across an orifice, the process of which is similar to a pre-chamber system, and showed that G-equation model with RANS turbulence model is a feasible approach to describe the flame evolution process. Kim et al. [9] compared G-equation and well-stirred reactor (WSR) model in RANS simulation of a pre-chamber SI natural gas engine and the predictions with both combustion models are quite accurate. However, the combustion process in the dual-fuel pre-chamber engines is quite complicated and differs in pre- and main chambers, which is believed to include multiple combustion regimes such as non-premixed flame, jet flame and premixed flame propagation [19-22]. Consequently, it is very challenging to apply a single turbulent combustion model to accurately describe the entire combustion process for a dual-fuel pre-chamber engine in a cost-effective manner.

Due to the aforementioned challenges, this work aims at the development of a modeling framework to accurately and efficiently capture the multi-regime combustion process in dual-fuel pre-chamber engines. Specifically, a first simulation run using the WSR model is performed until the initial stage of jet flame emergence, and then, a second simulation run is initiated applying the G-equation model with mapped fields from the first simulation. This modeling approach was applied in the simulation of a large-bore low-speed marine engine with a pre-chamber running on NG and HOF. The combustion process inside the pre- and main chambers were examined in detail using the representative exothermic reaction (RXR) analysis, and the jet flame was further investigated applying the premixed turbulent combustion regime diagram [23], which justifies the mapping approach connecting the WSR and G-equation models. The results show that in comparison with the simulations using WSR and G-equation alone, the proposed mapping approach provides the best compromise between computational cost and accuracy, suggesting the value of this approach in the R\&D of marine engines. 


\section{Engine Specifications and Operating Conditions}

The test engine is a two-stroke pre-chamber marine engine manufactured by China Shipbuilding Power Engineering Institute, which is designed for flexible operation on both HOF single-fuel and diesel-LNG dual-fuel engines. The gas admission valves (GAVs) are located at the two sides of cylinder and supply the gaseous fuel into the cylinder while the piston moving upward when operating in the dual-fuel mode. Pilot diesel fuel is injected into the pre-chamber through a three-hole, $0.42 \mathrm{~mm}$-orifice injector under 500 bar injection pressure. The detailed configuration of the test engine is shown in Figure 1a, and the close-up of the pre-chamber is shown in Figure 1b. The key parameters of the test engine are listed in Table 1, and the baseline operating conditions are listed in Table 2. In this work, the top dead center (TDC) was defined at the $0{ }^{\circ} \mathrm{CA}$, and the engine simulation runs from the exhaust valve opening (EVO, seen in Table 2 ) and for a $360-^{\circ} \mathrm{CA}$-period complete cycle, including the scavenging process to provide accurate in-cylinder flow and thermodynamic conditions. Data on the test engine were used to evaluate and validate numerical models.

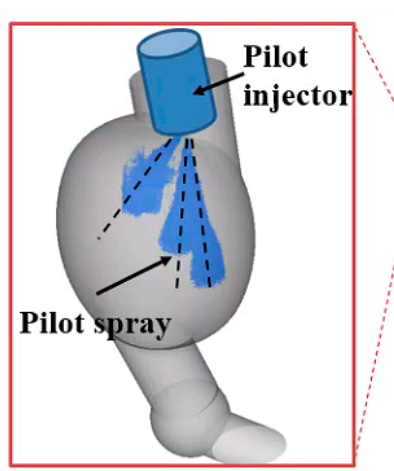

(b)
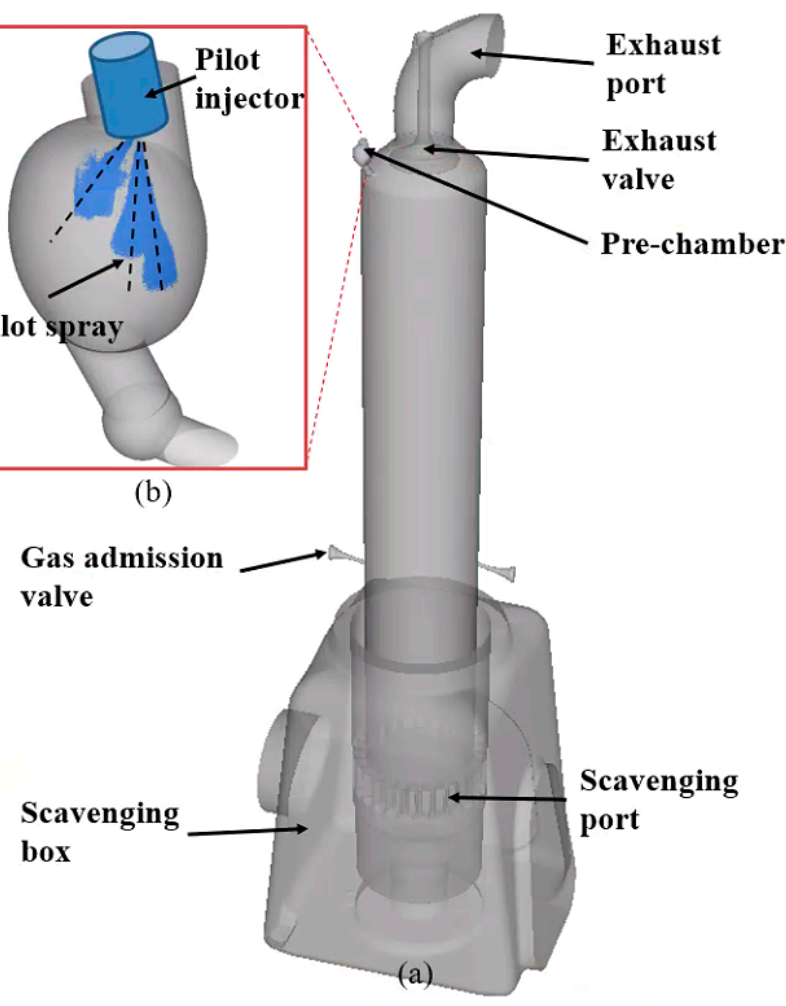

Figure 1. (a) Configuration of the dual-fuel marine engine, (b) close-up of the pre-chamber and pilot spray path.

Table 1. Engine specifications.

\begin{tabular}{cc}
\hline Items & Values \\
\hline Bore $\times$ stroke $/ \mathrm{mm}$ & $400 \times 2350$ \\
Compression ratio & 12.0 \\
Pre-chamber count & 1 \\
Pre-chamber volume $/ \mathrm{L}$ & 0.175 \\
Channel orifice $\Phi \times \mathrm{L} / \mathrm{mm}$ & $16 \times 20$ \\
Pilot injector nozzle diameter $/ \mathrm{mm}$ & $3 \times 0.42$ \\
\hline
\end{tabular}


Table 2. Baseline operating conditions.

\begin{tabular}{cc}
\hline Items & \\
\hline Load/\% & 75 \\
Speed/rpm & 95.6 \\
Overall fuel/air equivalence ratio & 0.38 \\
Cyclic gas fuel mass/g & 19.2 \\
Cyclic pilot fuel mass/g & 0.12 \\
Start of pilot injection $/{ }^{\circ}$ CA ATDC & -7.9 \\
Pilot injection pressure/bar & 500 \\
\hline
\end{tabular}

\section{Numerical Methods and Simulation Case Setup}

\subsection{Mapping Method and Numerical Models}

In this work, a three-dimensional (3D) computational fluid dynamic (CFD) model of the test engine is set up on CONVERGE V2.3 platform. Some of the sub-model setup can be found in Table 3. For each simulation case, a first simulation run is performed using the WSR model with a reduced mechanism to simulate the diesel spray auto-ignition and part of jet flame development, and it runs from EVO until the map timing $\left(T_{m}\right)$. Then, a second simulation run is started at $T_{m}$ with the initial fields of temperature, pressure, species and flow mapped from the first run and employs the G-equation model for flame propagation, as illustrated in Figure 2. The choice of $T_{m}$ is usually around the early stage of jet flame emergence into the main chamber when the combustion regime transitions from the turbulent flame jet to flame propagation, as will be discussed in detail in Sections 3.3 and 4.2. For comparison, simulations using WSR alone and G-equation alone are also performed.

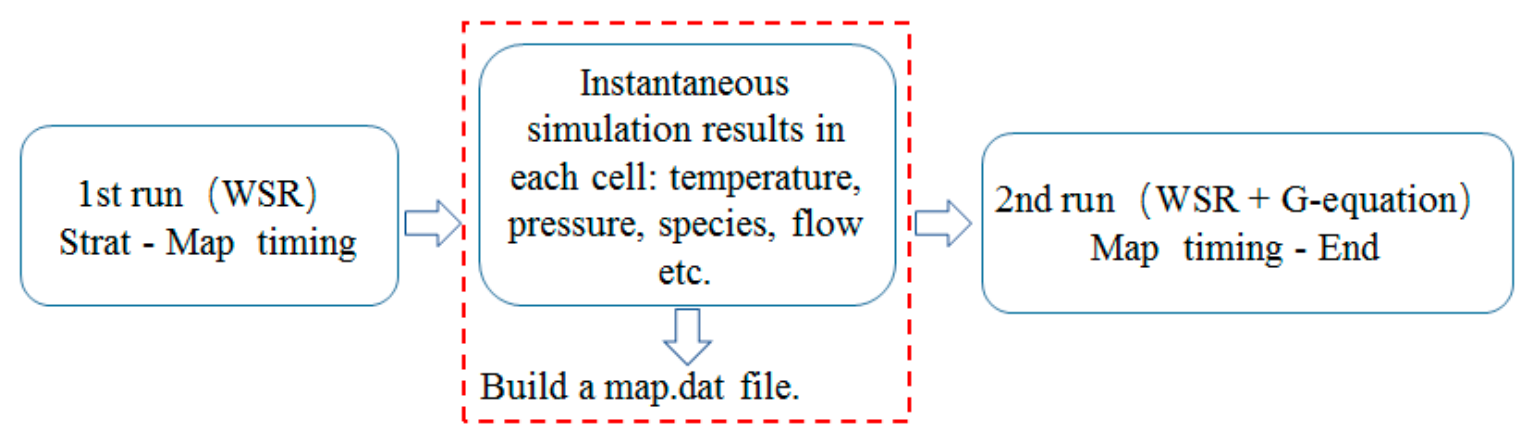

Figure 2. The flow chart of the mapping method for dual-fuel pre-chamber engine simulation.

The physical and chemical properties of diesel are approximated as those of ndodecane and n-heptane, respectively, and the natural gas is approximated as methane. For WSR model, a reduced chemical kinetic mechanism of methane/n-heptane with 79 species and 262 reactions [24] was employed to simulate the natural-gas/diesel dual-fuel combustion. This chemical mechanism was validated for both methane and n-heptane combustion experiments and showed quite good agreement with the experiments in terms of laminar flame speed and ignition delay. In addition, the multi-zone model [25] is employed with WSR in order to accelerate the solution of detailed chemical kinetics, which groups the computational cells with similar composition and thermodynamic states in the chemistry calculation. 
Table 3. CFD sub-model setup.

\begin{tabular}{cc}
\hline Description & Model \\
\hline Turbulence & RNG k- $\varepsilon$ [26] \\
Spray break-up & KH-RT [27] \\
Ignition/combustion & Well-stirred reactor (WSR) model [24,28] \\
$\mathrm{NO}_{x}$ emission & G-equation with Gulder [29] correlation \\
& Extended Zeldovic's [30] \\
\hline
\end{tabular}

In the second run, the G-equation model is used to describe flame propagation, and the WSR model is only applied in the burnt zone for emission prediction. In the G-equation model, the flame front can be tracked by solving the transport equation of distance function $G$, as follows [31]:

$$
\frac{\partial \rho G}{\partial t}+\frac{\partial \rho u_{i} G}{\partial x_{i}}=-D_{t}^{\prime} k\left|\frac{\partial G}{\partial x_{i}}\right|+\rho_{u} S_{t}\left|\frac{\partial G}{\partial x_{i}}\right|
$$

where $S_{t}$ is the turbulent flamespeed, $\rho_{u}$ is the unburned density, and $k$ is the turbulent kinetic energy. The turbulent diffusivity terms are given by:

$$
D_{t}^{\prime}=\sqrt{c_{s} \frac{k}{2} \frac{c_{\mu}}{s_{c}} G^{\prime \prime 2}}
$$

where $S_{c}$ is the turbulent Schmidt number, and $c_{s}$ is a user-supplied constant.

The turbulent flame speed $S_{t}$ is calculated in the RANS framework as follows [32]:

$$
S_{t}=S_{l}+u^{\prime}\left\{-\frac{a_{4} b_{3}^{2}}{2 b_{1}} D a+\left[\left(\frac{a_{4} b_{3}^{2}}{2 b_{1}} D a\right)^{2}+a_{4} b_{3}^{2} D a\right]^{1 / 2}\right\}
$$

where $S_{l}$ is the laminar flame speed, and the second term on the right hand side is the turbulence correction including three modeling constants $a_{4}, b_{1}, b_{3}$ and the non-dimensional Damkohler number $(D a)$. Correspondingly, the turbulence correction term is positively correlated with the turbulence intensity $\left(u^{\prime}\right)$ and $D a$. The expression of $S_{l}$ is given by Gulder [29] as:

$$
\begin{gathered}
S_{l_{\_} r e f}=\omega \varphi^{\eta} \exp \left[-\xi(\varphi-1.075)^{2}\right] \\
S_{l}=S_{l_{\_} r e f}\left(\frac{T_{u}}{T_{u_{\_} r e f}}\right)^{\gamma}\left(\frac{P}{P_{\text {ref }}}\right)^{\beta}\left(1-2.1 \gamma_{\text {dil }}\right)
\end{gathered}
$$

where $T_{u_{\_} r e f}$ is the reference unburned temperature, $T_{u}$ is the unburned temperature, $P_{\text {ref }}$ is the reference pressure, and $\gamma_{-}$dil is the mass fraction of dilution species. $\gamma$ and $\beta$ are correction exponents for temperature and pressure, respectively. The typical values of the constants mentioned are summarized in Table 4 for simulating the $\mathrm{CH}_{4}$ flame. In addition, for jet flame simulation in this work, the turbulence correction modeling constants $b_{1}$ and $b_{3}$ are adjusted in calibration with the experiments.

Table 4. Model constants and typical value in the G-equation model.

\begin{tabular}{cccccccccc}
\hline Constant & $\boldsymbol{a}_{\mathbf{4}}$ & $\boldsymbol{b}_{\mathbf{1}}$ & $\boldsymbol{b}_{\mathbf{3}}$ & $\boldsymbol{\omega}$ & $\boldsymbol{\eta}$ & $\boldsymbol{\xi}$ & $\gamma$ & $\boldsymbol{\beta}$ & $\boldsymbol{C}_{S}$ \\
\hline Typical value & 0.78 & 2.0 & 1.0 & 0.422 & 0.15 & 5.15 & 2.0 & -0.5 & 2.0 \\
\hline
\end{tabular}

\subsection{Meshing Details}

For simulation of a two-stroke low-speed marine engine, the computational mesh needs to be carefully setup due to its huge size compared to an automobile engine. CONVERGE provides a modified cut-cell Cartesian grid generation method to automatically generate the computational grid at runtime and allows for regional grid embedding and 
adaptive mesh refinement (AMR) according to the local condition [32]. In this work, in addition to the base grid, fixed embedding of level 2 is applied in the pre-chamber and AMR of level 2 with respect to temperature, and velocity is applied in the main chamber. A series of cases with a different choice of base grid size of $20 \mathrm{~mm}$ and $10 \mathrm{~mm}$ are set up with both two models as shown in Table 5 to investigate the effects of meshing on simulation results using different models.

Table 5. Mesh details and simulation time cost under different grid size.

\begin{tabular}{|c|c|c|c|c|c|c|}
\hline Case ID & $\begin{array}{l}\text { Base Grid } \\
\text { Size/mm }\end{array}$ & $\begin{array}{l}\text { Min. Grid } \\
\text { Size/mm }\end{array}$ & $\begin{array}{c}\text { Peak Cell } \\
\text { Count }\end{array}$ & $\begin{array}{c}\text { Cell Count at } \\
\text { TDC }\end{array}$ & $\begin{array}{c}\text { Combustion } \\
\text { Model }\end{array}$ & $\begin{array}{l}\text { Runtime on } \\
112 \text { Cores/h }\end{array}$ \\
\hline 1 & 20 & 5 & $1200 \mathrm{~K}$ & $450 \mathrm{~K}$ & \multirow{2}{*}{ WSR } & 96 \\
\hline 2 & 10 & 2.5 & $7500 \mathrm{~K}$ & $2800 \mathrm{~K}$ & & 188 \\
\hline 3 & 20 & 5 & $1200 \mathrm{~K}$ & $450 \mathrm{~K}$ & \multirow{2}{*}{ G-equation } & 36 \\
\hline 4 & 10 & 2.5 & $7500 \mathrm{~K}$ & $2800 \mathrm{~K}$ & & 135 \\
\hline
\end{tabular}

\subsection{Tm and Turbulent Flame Speed Model Constant}

As mentioned in Section 3.1, the $T_{m}$ is a key parameter that determines when Gequation starts to work in the computational model. In order to shed insight into the choice of $T_{\mathrm{m}}$, three cases with different $T_{m}$ are set up in this section and compared to the baseline case using WSR alone (case 1) and the case using G-equation alone (case 3), as seen in Table 6.

Table 6. $T_{m}$ and the case simulation time cost.

\begin{tabular}{cccc}
\hline Case ID & $\boldsymbol{T}_{\boldsymbol{m}} /$ CA ATDC & Runtime on 112 Cores/h & Combustion Model \\
\hline 1 & - & 96 & WSR model \\
\hline 3 & - & 36 & G-equation \\
\hline 5 & 353.8 & 46 & \\
6 & 352.8 & 43 & WSR $\rightarrow$ G-equation \\
7 & 351.8 & 40 & \\
\hline
\end{tabular}

As introduced in Equation (3), the turbulent flame speed prediction is dependent on the turbulence correction term, which is affected by model constants $a_{4}, b_{1}$ and $b_{3}$. These constants are often used as tuning knob to accommodate the variation in turbulence-chemistry interaction and to optimize prediction accuracy. Hence, typical values as recommended by Peters [31], as well as 2 groups of constants using higher values for $b_{1}$ and $b_{3}$, are adopted in this study, as detailed in Table 6. The use of large values for $b_{1}$ and $b_{3}$ is necessary to match the experiments, which is also observed in other studies [33]. Note that the mesh setup of case 1 is adopted for all the cases in Tables 6 and 7.

Table 7. Modeling constants study cases.

\begin{tabular}{ccccc}
\hline ID & Combustion Model & $\boldsymbol{a}_{\mathbf{4}}$ & $\boldsymbol{b}_{\mathbf{1}}$ & $\boldsymbol{b}_{\mathbf{3}}$ \\
\hline $\mathrm{G}_{\text {-typical }}$ & & 0.78 & 2.0 & 1.0 \\
$\mathbf{G}_{\mathbf{1}}$ & G-equation & 0.78 & 30.0 & 13.0 \\
$\mathrm{G}_{\mathbf{2}}$ & & 0.78 & 15.0 & 9.0 \\
\hline
\end{tabular}

Another parameter, $C$, is defined to describe the combustion heat release progress of pilot fuel as follows:

$$
C=\frac{q}{Q}
$$

where in $q$ is the integrated heat release, and $Q$ is the calorific value of pilot fuel. Considering the heat release by both two fuels cannot be decoupled, $C$ is inevitable larger than 1 when pilot fuel is completed burned. 


\subsection{Flame Structure Analysis}

$D a$ is a key parameter for elucidation of the flame structure and is defined as the ratio of mixing time scale $\left(\tau_{l}\right)$ and chemical time scale $\left(\tau_{F}\right)$ :

$$
D a=\frac{\tau_{l}}{\tau_{F}}=\frac{s_{l} l_{t}}{l_{F} u^{\prime}}
$$

where $s_{l}$ is the laminar flame speed and can be estimated using the Gulder's model [29]. $l_{F}$ is the flame front thickness, and $l_{t}$ is the integral length scale. $u^{\prime}$ is the turbulent fluctuating

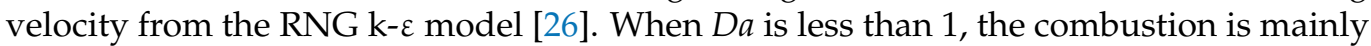
controlled by chemical kinetics, while the combustion process is characterized by fast chemistry when $D a$ is larger than 1 [34]. In this work, flame front is defined as the $1400 \mathrm{~K}$ temperature isosurface $[35,36]$, as shown by the red isosurface in Figure 3. In addition, the flame tip is defined as the cross of flame front and the axial centerline of channel orifice. Along the orifice direction, simulation data of $D a, u^{\prime}$, turbulent flame speed (St) in each cell and the corresponding distance from orifice exit are extracted for several time instants to illuminate the flame structure variation. Refer to $\mathrm{Xu}$ et al. [37] for the Da calculation method. When the G-equation model is applied, the turbulent flame speed in each cell can be output directly, while when the WSR model is applied, the turbulent flame speed is derived as the movement rate of $1400 \mathrm{~K}$ isosurface through post-processing.

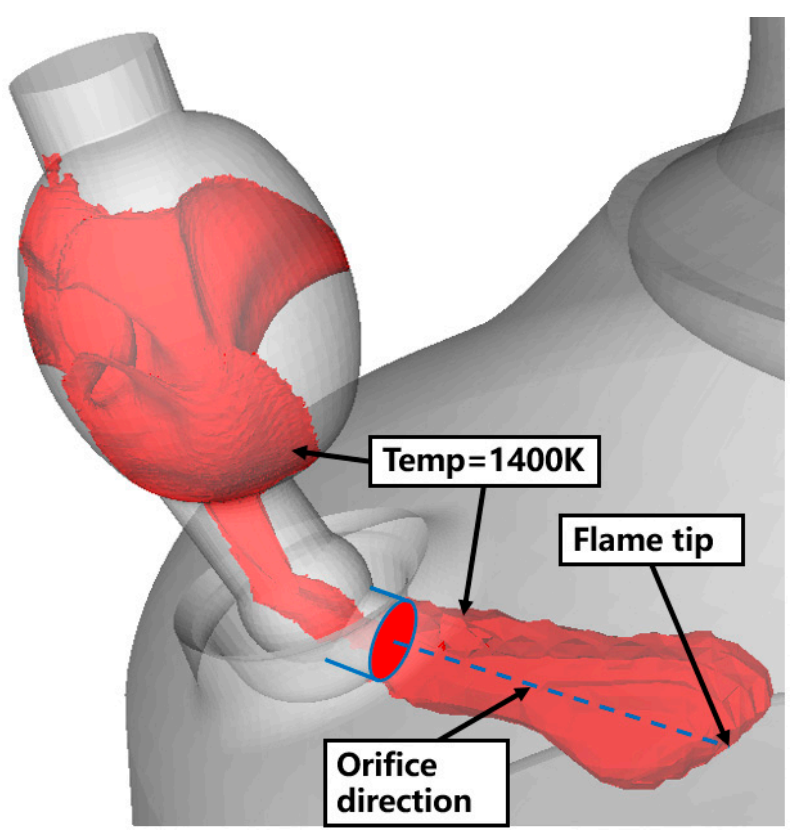

Figure 3. Isosurface of temperature at $1400 \mathrm{~K}$ (red) and the location of flame tip.

In addition, the RXR analysis is applied here to further investigate the flame structure at the mapping timing to illustrate the chemical process. The RXR in each cell was identified as the reaction that makes the highest contribution to the local heat release using a postprocessing code developed by Liu et al. [38].

\section{Results and Discussion}

\subsection{Comparative Analysis of WSR, G-Equation and the Mapping Approach}

The model accuracy and grid sensitivity are evaluated by comparing the simulation results to the experimental data. Figure 4 compares the experimental and predicted incylinder pressure and HRR of case setups in Table 5, employing two combustion models on meshing setup with minimum grid sizes 5 and $2.5 \mathrm{~mm}$, respectively. It is obvious that the WSR model is more sensitive to the grid size, wherein simulation results using a finer computational grid match the experimental data better compared to the coarser 
one. In contrast, negligible differences between two mesh setups are noticed when using the G-equation model. Furthermore, even under a $2.5 \mathrm{~mm}$-scale computational grid, the predicted results using the WSR model match the experiment only for the early combustion stage (before $353{ }^{\circ} \mathrm{CA}$ ) but show a much slower heat release rate from 353 to $365{ }^{\circ} \mathrm{CA}$, which leads to the delayed HRR at around $375^{\circ} \mathrm{CA}$. Employing a much finer grid could be beneficial to the WSR simulation results; however, it is prohibitively expensive in computational cost, since the marine engine as investigated in this study is significantly larger than a typical automobile engine, and the speed is also much lower.

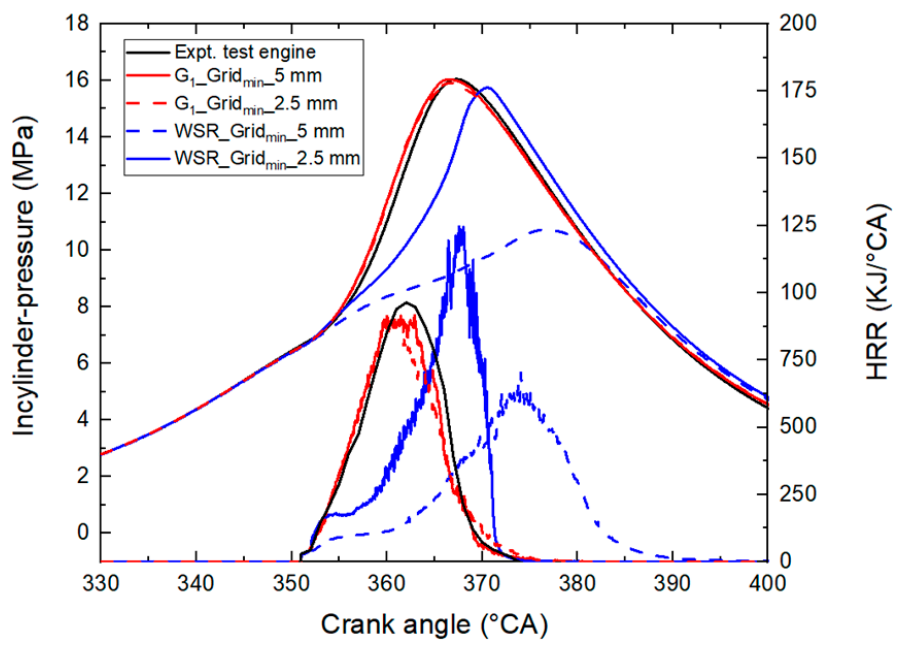

Figure 4. Experimental and predicted in-cylinder pressure and HRR of cases setup in Table 5.

On the other hand, cases using G-equation cost less run time (see Table 5), which is more favorable for large-bore engine R\&D activity. In addition, the results of cases employing G-equation are closer to experimental data during the entire combustion process. However, the G-equation model also has its drawbacks for such a multi-stage combustion process. Figure $5 b$ shows that the flame front in the pre-chamber develops spherical flame propagation using the G-equation model in case 3, and it is quite different compared to the results of the WSR model, as shown in Figure 5a. The diesel spray combustion process in premixed methane/air mixture is expected to occur in the pre-chamber, which is similar to the results in Figure 5 a according to optical engine studies [38,39]. The flame development in case 3 is significantly slower than that in case 1 , whereas the jet flame in case 1 has already entered the main chamber at $351.7^{\circ} \mathrm{CA}$ but the flame in case 3 has not reached the exit yet at $352{ }^{\circ} \mathrm{CA}$. Therefore, it is not appropriate to apply the G-equation model alone for the multi-regime combustion in the dual-fuel pre-chamber engine, as it is designed for turbulent premixed combustion rather than liquid fuel spray combustion. In addition, a slow combustion rate inside the pre-chamber leads to underpredicted NOx emission with the G-equation model (seen in Section 4.2 in details), since most NO $x$ is generated inside the pre-chamber according to the previous work [40].

Therefore, neither WSR nor G-equation used solely can accurately predict the complex combustion process in the engine using premixed natural gas fuel ignited by diesel spray inside the pre-chamber. More specifically, the WSR model is more appropriate to predict diesel spray combustion, while G-equation can simulate jet flame and the subsequent flame propagation process in the main combustion chamber. Hence, a mapping method combining both models for different combustion stages in such a dual fuel pre-chamber engine is set up.

Figure 6 shows the in-cylinder pressure and HRR of experimental and simulation results with the single G-equation model, WSR model, and mapping method connecting both models. The mapping timing applied here is $353.8^{\circ} \mathrm{CA}$, and the choice of mapping timing will be discussed in the next section. In order to optimize simulation results, two groups of different model constants named $G_{1}$ and $G_{2}$, respectively, are used for the $G_{-}$ 
equation model, as listed in Table 7. From Figure 6, we can see that using the combined WSR and G-equation model through the mapping method (case 6) shows better prediction accuracy compared to the other two. Specifically, although it shows little difference in heat release rate in early combustion stage, the process inside the pre-chamber is better described by the mapping approach using the WSR model for this period compared to the G-equation model, as discussed above and illustrated in Figure 5. For the following combustion stage (from 353.8 to $360^{\circ} \mathrm{CA}$ ), the mapping approach shows faster heat release than employing WSR alone, because the mapping approach employs G-equation for this period to achieve less grid-dependency. Figure 7 summarizes the temporal $S_{t}$ at the flame tip (defined as shown in Figure 3) after the flame develops into the main chamber of the cases with different models. The starting points of lines correspond to the timing of flame emergence into the main chamber, and the earlier flame emergence using the mapping approach is consistent with the previous discussion. It is obvious that the flame development process inside the main chamber includes three stages according to the flame speed profile, which was also observed in direct numerical simulation results of pre-chamber jet flame [21]. This three-stage flame development exists for all three model setups as seen in Figure 7; although the specific timings and durations are different from the results of Figure 7, we can see that employing the G-equation model after map timing $\left(353.8^{\circ} \mathrm{CA}\right)$ can slow down the reduction rate of flame speed and achieve a better match against the experiment for the heat release prediction.

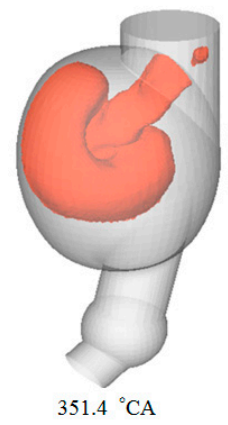

$351.4{ }^{\circ} \mathrm{CA}$

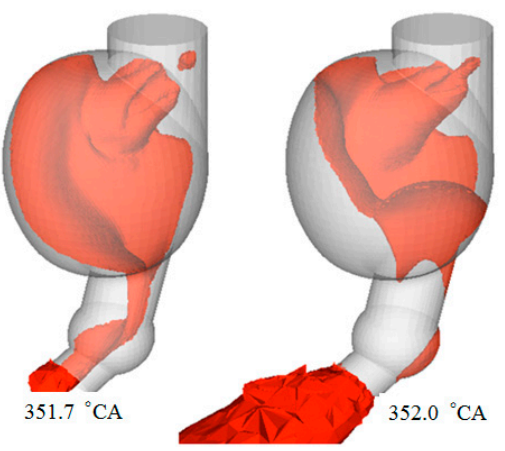

(a)

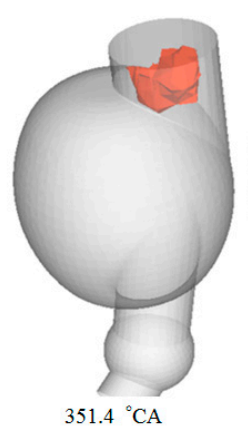

$351.4^{\circ} \mathrm{CA}$
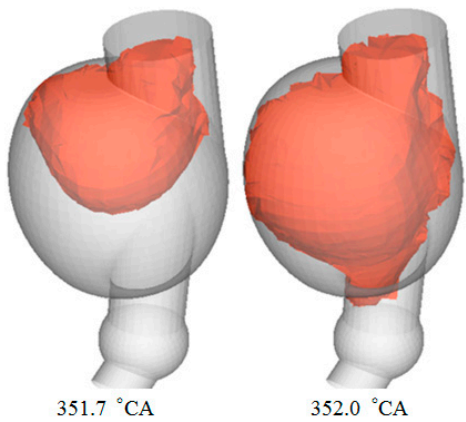

(b)

Figure 5. Development of flame front in pre-chamber of (a) case 1 and (b) case 3. Flame front defined as $1400 \mathrm{~K}$ isosurface.

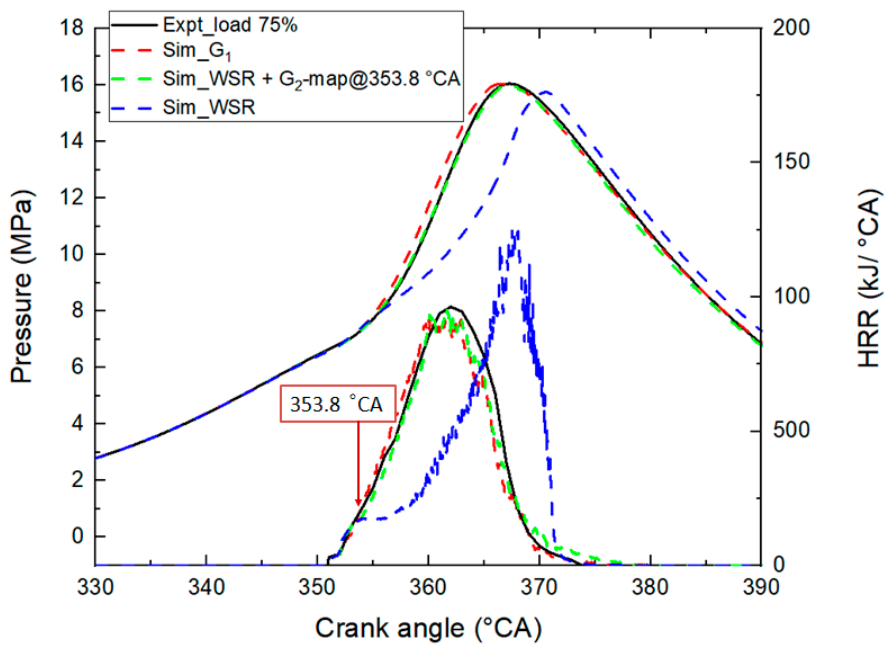

Figure 6. In-cylinder pressure and HRR of experimental and simulation results with different flame development models. 


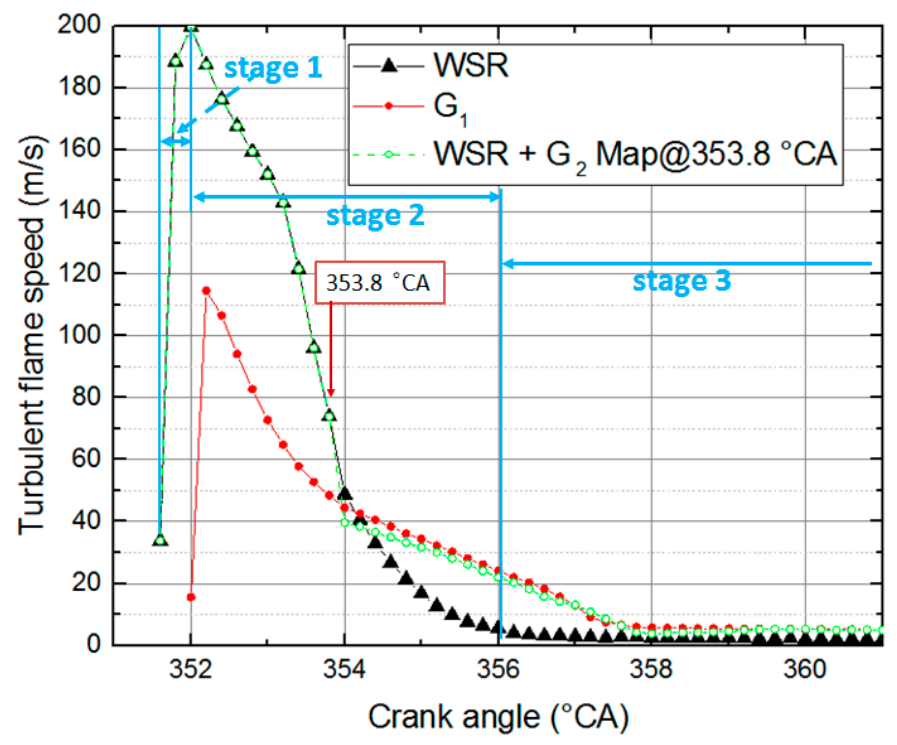

Figure 7. $S_{t}$ at flame tip of the cases with different models.

\subsection{Flame Structure Analysis and Choice of Tm}

The mapping timing $T_{m}$ is determined as $353.8^{\circ} \mathrm{CA}$ for this studied condition mainly based on calibration rather than in a predictive manner, and it is necessary to further discuss the choice of $T_{m}$ to improve the predictivity of this approach. In this section, the flame structure evolution based on parameters of $u^{\prime}, D a$ and the Borghi-Peters diagram is analyzed in detail.

Local temperature, $u^{\prime}$ and $D a$ in each simulation cell along the orifice centerline (seen in Figure 3) using WSR alone or the G-equation model $\left(\mathrm{G}_{1}\right)$ alone are provided in Figures 8-10, respectively. The temperature profiles show that flame development speeds predicted by the two models are remarkably different. Specifically, at $352{ }^{\circ} \mathrm{CA}$, jet flame length is a bit longer using the WSR model than using G-equation; however, flame length shows the opposite result after $353^{\circ} \mathrm{CA}$, which indicates that the simulated flame develops faster with the WSR model at the early stage of the jet flame development process, while later on, the simulated flame develops more slowly using WSR model. Figure 9 shows local $u^{\prime}$ results at different times using the two models. It is obvious that the $u^{\prime}$ of the flame is profoundly larger at $352{ }^{\circ} \mathrm{CA}$ than later on. Results using two models show very similar trends, while only the flame lengths are different, as earlier mentioned. The change in $u^{\prime}$ indicates that the flame structure changed significantly after $352{ }^{\circ} \mathrm{CA}$, which is captured by the simulations with either the WSR model or G-equation. In Figure 10, $D a$ results show that large $D a$ appears at the location nearby the flame tip, especially after $354{ }^{\circ} \mathrm{CA}$. Although the magnitudes are quite different using the two models, which is due to the differences in predicted flame speed and $l_{\mathrm{t}} / l_{\mathrm{f}}$, the overall trends of $D a$ changing with time for each model are consistent. The scatter points in the Borghi-Peters diagram of two models at different times as shown in Figure 11 can further illustrate the flame structure change. The jet flame is initially close to the broken reaction zones and is always in thin reaction zones. Then, it moves towards the corrugated flamelet zones, which is more profound when using the G-equation model. Furthermore, after $353^{\circ} \mathrm{CA}$, the scatter points cross the line of $D a=1$ towards larger values, meaning that fast chemistry dominates the flame, and the flame front can be tracked with a level-set approach, i.e., the G-equation model, as suggested by Peters [31]. 


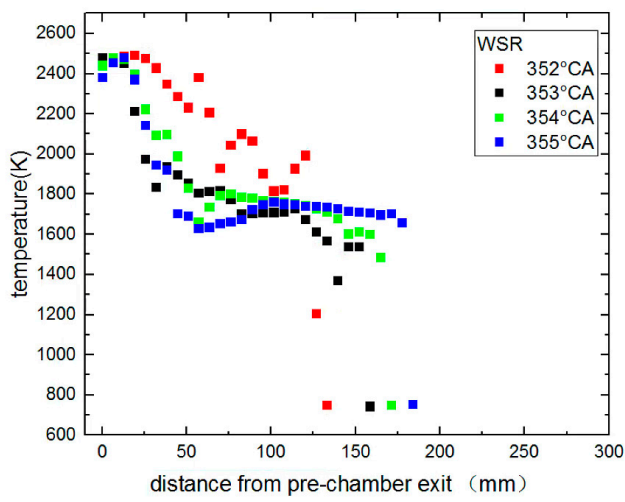

(a)

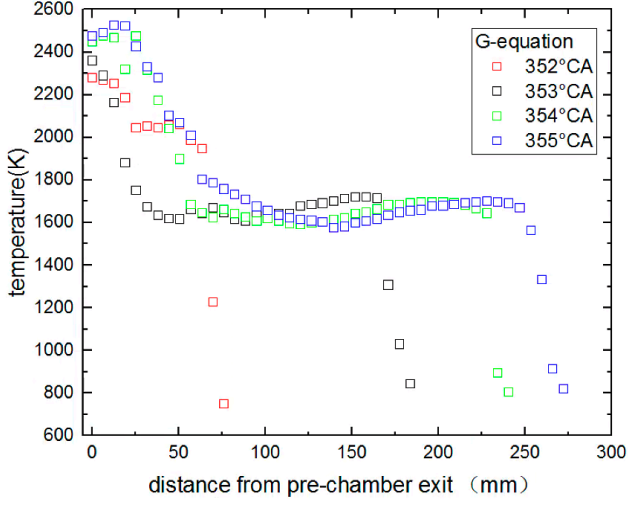

(b)

Figure 8. Local temperature results and the corresponding distance from pre-chamber exit at different times, using (a) the WSR model and (b) the G-equation model.

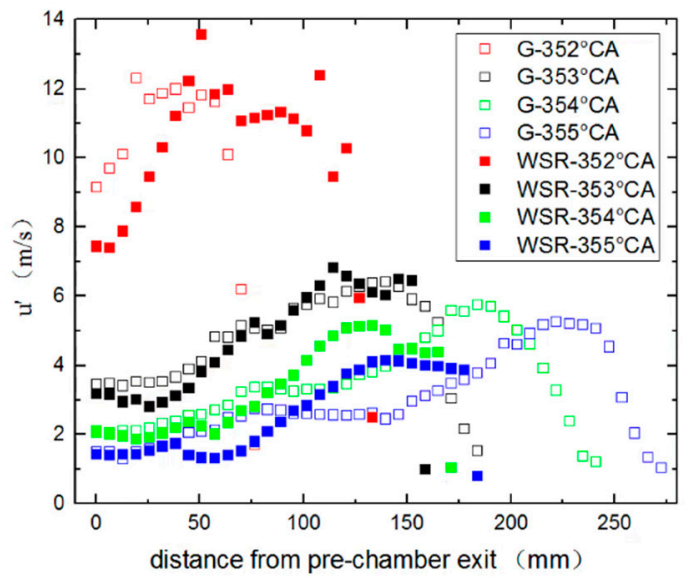

Figure 9. Local turbulence intensity $\left(u^{\prime}\right)$ results and the corresponding distance from pre-chamber exit at different times, using the WSR model and the G-equation model.

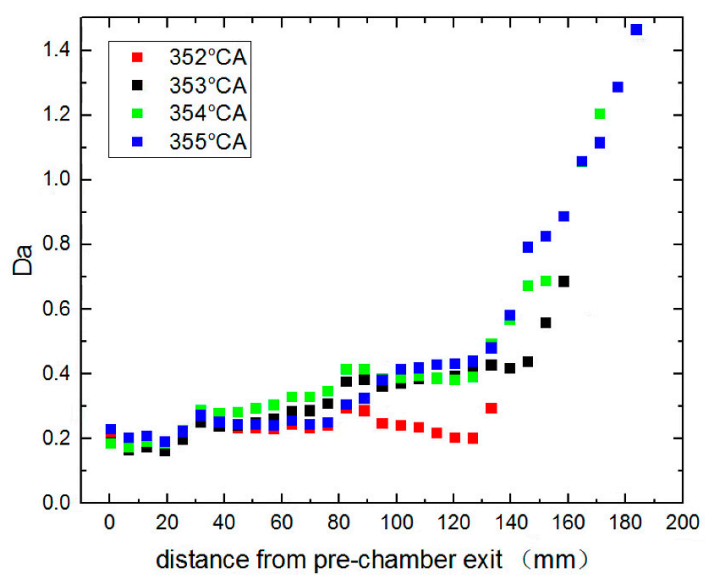

(a)

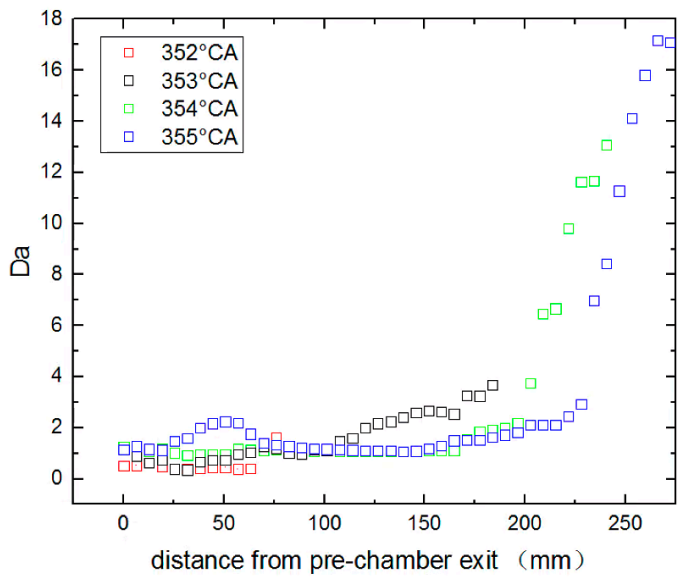

(b)

Figure 10. Local Damkohler number $(D a)$ results and the corresponding distance from pre-chamber exit at different times, using (a) the WSR model and (b) the G-equation model. 


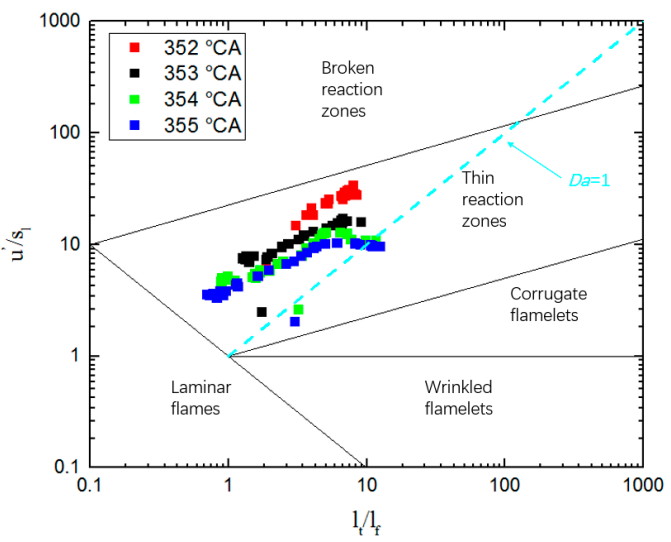

(a)

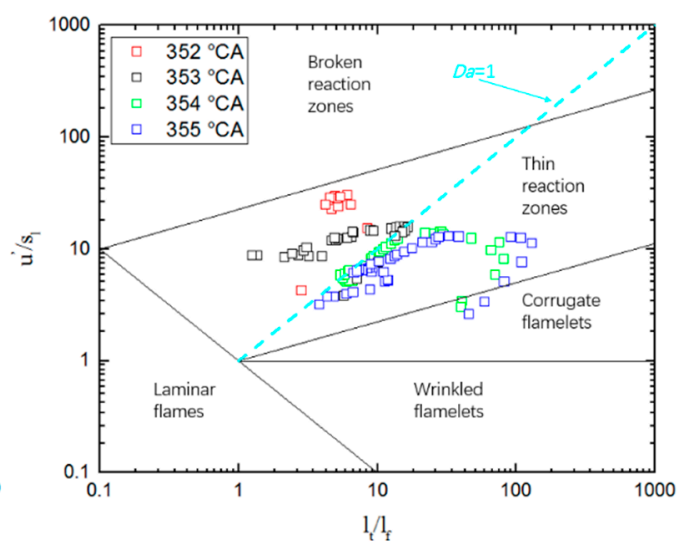

(b)

Figure 11. The discrete points of jet flame in the Borghi-Peters diagram [27] at different times, using (a) the WSR model and (b) the G-equation model.

In order to further understand the flame structure, the RXR distribution on the clip plane along the jet direction for case 3 at $353.8^{\circ} \mathrm{CA}$ ( $T_{m}$ in case 5 ) is shown in Figure 12, and the corresponding formation and production rate of methyl are shown in Figure 13. As can be seen, similar RXR occurs inside the pre-chamber and jet flame core near the exit, which suggests the burning mixture in the pre-chamber is pushed into the main chamber along with the jet, and the reaction status is not changed much during this process. In addition, the reaction at the periphery of the jet is mainly participated by methyl, which is mainly from the premixed $\mathrm{CH}_{4}$ reaction according to the analysis in Figure 13. This justifies the use of G-equation to describe flame propagation in premixed $\mathrm{CH}_{4}$ in the mapping approach.

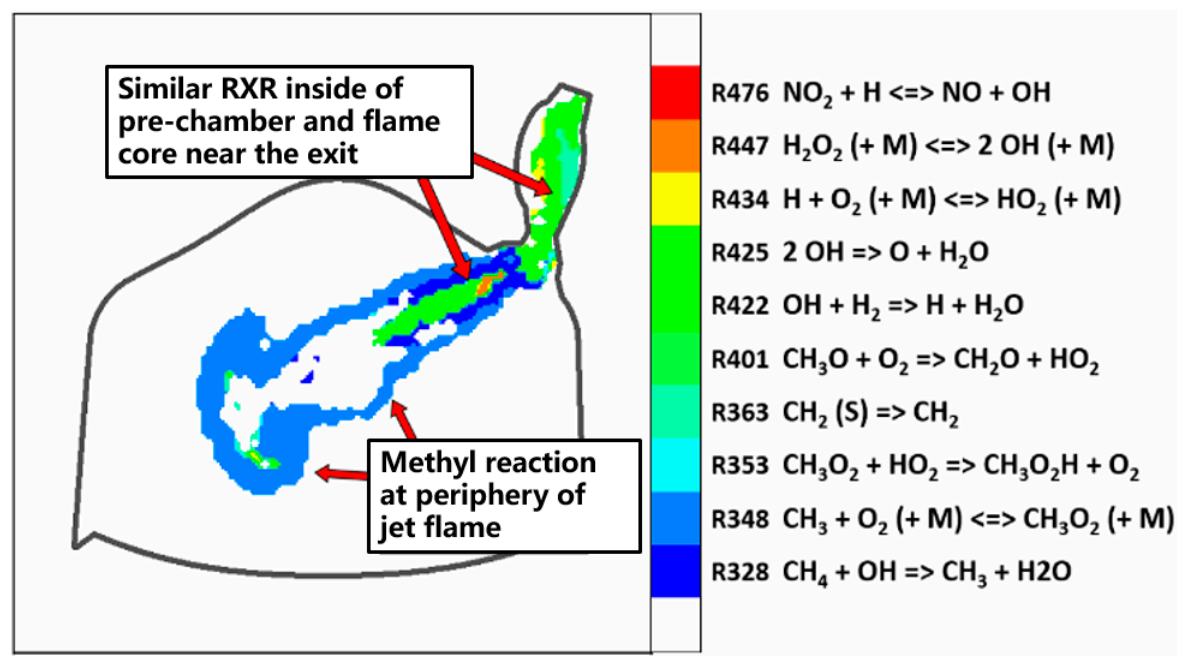

Figure 12. RXR distribution at $353.8^{\circ} \mathrm{CA}$, and the clip plane is along the jet direction axis and vertical direction.

Using a key parameter as the formally simple approach to choose the $\mathrm{T}_{m}$ is ideal in engineering application. In this section, the mean turbulence intensity $\bar{u}^{\prime}$, the overall $\mathrm{NO}_{x}$ emission level and the combustion schedule parameter $C$ are considered tentatively to determine $T_{m}$.

Figure 14 shows the simulated mean turbulence intensity $\bar{u}^{\prime}$ results, defined as statistics data of the region inside the flame surface in main chamber. $\bar{u}^{\prime}$ declines as the flame development proceeds. In addition, the results of two models show a considerable difference when $\bar{u}^{\prime}$ reduces below $4 \mathrm{~m} / \mathrm{s}$, and the corresponding crank angle is at $353.8^{\circ} \mathrm{CA}$ ( $T_{m}$ in case 5). Thus, choosing the crank angle when $\bar{u}^{\prime}=4 \mathrm{~m} / \mathrm{s}$ as $T_{m}$ may be reasonable. 
Table 8 shows the IMEP and $\mathrm{NO}_{x}$ emission prediction results of cases $3,5,6$ and 7 . As can be seen, using the G-equation model alone (case 3) or when $T_{m}$ is early (cases 6 and 7), which means WSR does not run long enough for flame development prediction, leads to $\mathrm{NO}_{x}$ emissions a bit lower than in experimental data, while $T_{m}=353.8^{\circ} \mathrm{CA}$ (case 5) shows the best simulated result. On the other hand, although the IMEP result of case 5 shows a higher discrepancy against experimental data, it is still considered within the acceptable range compared to the errors seen for $\mathrm{NO}_{x}$ prediction. As mentioned, the $\mathrm{NO}_{x}$ emission is mainly produced in the pre-chamber and is dominated by the first combustion stage duration. Hence, choosing $T_{m}$ based on the calibration of $\mathrm{NO}_{x}$ emissions may also be a reasonable option. Besides, $\mathrm{C}$ at $T_{m}$ is also listed in Table 8 , as discussed previously, and the flame structure is changed significantly at $354^{\circ} \mathrm{CA}$; hence, $C=13.3$ (case $5, T_{m}=353.8^{\circ} \mathrm{CA}$ ) can also be considered as an indicator for combustion mode transition. In addition, when $T_{m}$ is too small (case 7), $C$ is less than 1 , meaning pilot fuel has not completely burned yet. When using the crank angle at $C=4.8$ as $T_{m}$ (case 6), the result shows underpredicted $\mathrm{NO}_{x}$ emissions compared to experimental data. Therefore, given the limited experimental data, the choice of $T_{m}=353.8^{\circ} \mathrm{CA}$ provides the most accurate and reasonable results, and three indicators of $\bar{u}^{\prime}, \mathrm{NO}_{x}$ emissions and $C$ can be potentially used to determine the mapping timing $T_{m}$ for engineering application.

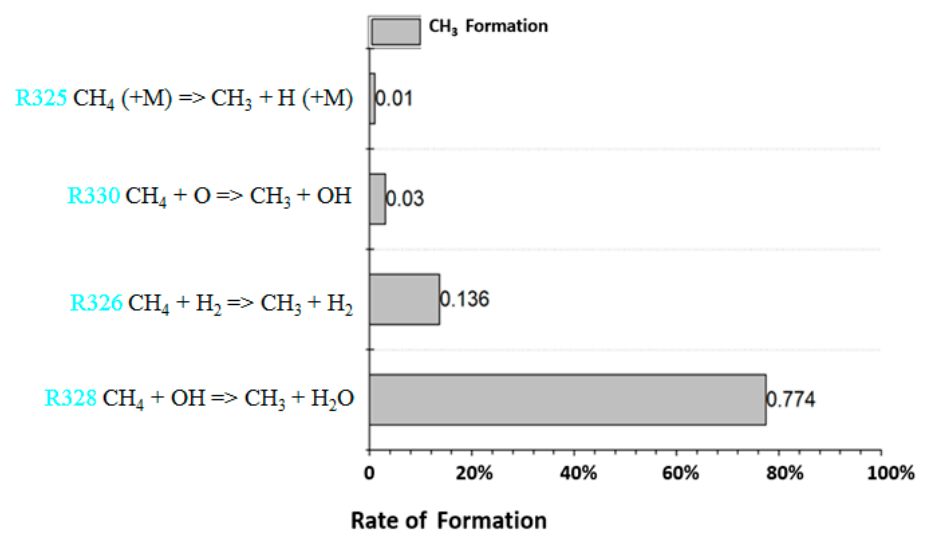

Figure 13. Formation rate of methyl for major reactions that account for more than $1 \%$ at $353.8^{\circ} \mathrm{CA}$ in the clip plane, same as Figure 12.

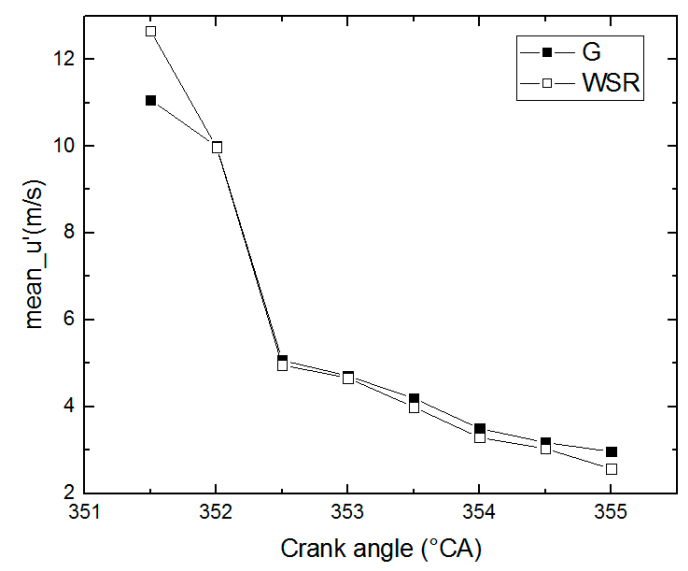

Figure 14. The mean turbulence intensity of jet flame at different times, using the WSR model and the G-equation model. 
Table 8. IMEP and $\mathrm{NO}_{x}$ emission prediction results of cases 3, 5, 6 and 7 and the experimental data.

\begin{tabular}{cccccc}
\hline Case ID & IMEP/Bar & Error & NO $_{x}$ Emission/g.kwh $\mathbf{k n}^{-1}$ & Error & $\mathbf{C}_{\text {at }} \boldsymbol{T}_{\boldsymbol{m}}$ \\
\hline Expt. & 14.94 & - & 1.1 & - & - \\
3 & 14.92 & $0.13 \%$ & 0.65 & $-46.6 \%$ & - \\
5 & 15.45 & $3.41 \%$ & 1.07 & $-2.7 \%$ & 13.3 \\
6 & 15.21 & $1.80 \%$ & 0.89 & $-19.1 \%$ & 4.8 \\
7 & 15.02 & $0.54 \%$ & 0.78 & $-29.1 \%$ & 0.5 \\
\hline
\end{tabular}

\section{Conclusions}

An accurate and efficient numerical method to simulate combustion process for largebore dual-fuel marine engine with pre-chamber was proposed in this study. Firstly, a grid-dependency study was performed using the WSR model and G-equation with the RANS turbulence model to manifest that the WSR model is more sensitive to grid resolution compared to the G-equation model. Then, detailed RXR analysis and premixed turbulent combustion regime analysis were applied to better understand the characteristics of the pre-chamber flame jet, which also justifies the use of the mapping approach that couples the WSR and G-equation models to enable fast and accurate simulation. Furthermore, the choice of mapping timing $\left(T_{m}\right)$ was discussed, and three potential approaches to determine $T_{m}$ were proposed to improve the predictivity of this mapping approach for engineering application. Major conclusions are as follows:

1. The grid sensitivity study showed that a minimum mesh resolution of $2.5 \mathrm{~mm}$ cannot satisfactorily predict the combustion HRR and in-cylinder pressure using the RANS method coupled with the WSR model. However, it is quite unacceptable to use a further finer grid in engineering application. The G-equation model is not as grid sensitive as the WSR model, thus enabling faster simulation.

2. Employing G-equation alone for the combustion prediction can significantly reduce simulation time cost. However, the prediction of flame development and $\mathrm{NO}_{x}$ emission formation in the pre-chamber is unsatisfying using G-equation alone.

3. The flame structure and RXR analysis shows that flame structure changes significantly at around $354{ }^{\circ} \mathrm{CA}$. Besides, the flame propagation mainly occurs in the premixed $\mathrm{CH} 4$. Therefore, choosing $T_{m}$ around this crank angle shows the best calibrated result compared to the test data.

4. Three potential approaches to determine $T_{m}$ for engineering application are proposed, viz., the crank angle when $\bar{u}^{\prime}=4 \mathrm{~m} / \mathrm{s}$, when $\mathrm{NO}_{x}$ emission is closest to experimental data or when the combustion progress parameter $C=13.3$.

This work represents a first step towards a predictive and cost-effective simulation framework for a dual-fuel marine engine, which is very challenging, characterized by the complex combustion process and large computational domain. Further development and verification for the modelling approach based on more engine test data and optical diagnostic results will be conducted in a future work.

Author Contributions: Conceptualization, Y.Y. and Z.Y.; methodology, Z.Y.; software, Y.Y. and H.W.; validation, H.L. and M.Y.; formal analysis, Z.Y.; investigation, Y.Y.; resources, H.L.; data curation, C.W.; writing — original draft preparation, Y.Y.; writing—review and editing, Z.Y.; visualization, Y.Y.; supervision, M.Y.; project administration, H.L. and C.W.; funding acquisition, M.Y. All authors have read and agreed to the published version of the manuscript.

Funding: This research was funded by $400 \mathrm{~mm}$-bore Low-Speed Marine Dual-Fuel Principled Sample Machine Project, Project number MC-201501-D01-03 and the National Natural Science Foundation of China (NSFC), grant number 52006154.

Institutional Review Board Statement: Not applicable.

Informed Consent Statement: Not applicable.

Conflicts of Interest: The authors declare no conflict of interest. 


\section{References}

1. Adams, S. LNG as Ship Fuel. The Future—Today; Technical Report; DNV: Oslo, Norway, 2014; pp. 6-7.

2. Wik, C. Reducing medium-speed engine emissions. J. Mar. Eng. Technol. 2010, 9, 8. [CrossRef]

3. Christen, C.; Brand, D. IMO Tier III: Gas and Dual Fuel Engines as a Clean and Efficient Solution. In Proceedings of the CIMAC Congress, Shanghai, China, 13-17 May 2013; p. 187.

4. CIMAC. CIMAC White Paper 1 (2020)_Production Pathways for Hydrogen with a Zero Carbon Footprint; CIMAC: Winterthur, Switzerland, 2020.

5. Dimopoulos, P.; Bach, C.; Soltic, P.; Boulouchos, K. Hydrogen-natural gas blends fueling passenger engines: Combustion, emissions and well-towheels assessment. Int. J. Energy 2008, 33, 7224-7236. [CrossRef]

6. Kronholm, M. Demanding icebreaking LNG-powered icebreaking features the industry's most advanced technology. In Proceedings of the CIMAC Congress, Helsinki, Finland, 6-10 June 2016; p. 226.

7. Ahmed, S.A.; Zhou, S.; Zhu, Y.; Feng, Y.; Malik, A.; Ahmad, N. Influence of Injection Timing on Performance and Exhaust Emission of CI Engine Fuelled with Butanol-Diesel Using a 1D GT-Power Model. Processes 2019, 6, 299. [CrossRef]

8. Semin, R. A technical review of compressed gas as an alternative fuel for internal combustion engines. Am. J. Eng. Appl. Sci. 2008, 1,302-311.

9. Kim, J.; Scarcelli, R.; Som, S.; Shah, A.; Longman, D. Assessment of Turbulent Combustion Models for Simulating Pre-Chamber Ignition in a Natural Gas Engine. In Proceedings of the ASME 2019 Internal Combustion Engine Division Fall Technical Conference, Chicago, IL, USA, 20-23 October 2019.

10. Toulson, E.; Schock, H.J.; Attard, W.P. A Review of Pre-Chamber Initiated Jet Ignition Combustion Systems. SAE Powertrains Fuels Lubr. Meet. 2010, 112, 2603-2604.

11. Ott, M.; Nylund, I. The 2-stroke; low-pressure dual-fuel technology: From concept to reality. In Proceedings of the CIMAC World Congress, Helsinki, Finland, 6-10 June 2016.

12. WinGD. RT-flex50DF Technical Information-Manuals. 2015. Available online: https://www.wingd.com/en/products/rt-flex5 0df/ (accessed on 25 April 2019).

13. Biswas, S.; Tanvir, S.; Wang, H. On ignition mechanisms of premixed $\mathrm{CH} 4$ /air and $\mathrm{H} 2$ /air using a hot turbulent jet generated by pre-chamber combustion. Appl. Therm. Eng. 2016, 106, 925-937. [CrossRef]

14. Yue, Z.; Som, S. Fuel property effects on knock propensity and thermal efficiency in a direct-injection spark-ignition engine. Appl. Energy 2019, 281, 114221. [CrossRef]

15. Dahms, R.N.; Drake, M.C.; Fansler, T.D.; Kuo, T.-W.; Peters, N. Understanding Ignition Processes in Spray-Guided Gasoline Engines Using High-Speed Imaging and the Extended Spark-Ignition Model SparkCIMM. Part A: Spark Channel Processes and the Turbulent Flame Front Propagation. Combust. Flame 2011, 158, 2229-2244. [CrossRef]

16. Colin, O.; Truffin, K. A Spark Ignition Model for Large Eddy Simulation Based on an FSD Transport Equation (ISSIM-LES). Proc. Combust. 2011, 33, 3097-3104. [CrossRef]

17. Peters, N. Turbulent Combustion; Cambridge University Press: Cambridge, UK, 2000.

18. Wei, H.; Zhao, J.; Zhou, L.; Gao, D.; Xu, Z. Effects of the equivalence ratio on turbulent flame-shock interactions in a confined space. Combust. Flame 2017, 186, 247-262. [CrossRef]

19. Jamrozik, A.; Tutak, W.; Kociszewski, A.; Sosnowski, M. Numerical simulation of two-stage combustion in SI engine with prechamber. Appl. Math. Model. 2013, 37, 2961-2982. [CrossRef]

20. Gentz GR and Toulson E, Experimental Studies of a Liquid Propane Auxiliary Fueled Turbulent Jet Igniter in a Rapid Compression Machine. SAE Int. 2016, 1, 7-8. [CrossRef]

21. Qin, F.; Shahc, A.; Huang, Z.W.; Peng, L.N.; Tunestal, P.; Bai, X.S. Detailed numerical simulation of transient mixing and combustion of premixed methane/air mixtures in a pre-chamber/main-chamber system relevant to internal combustion engines. Combust. Flame 2018, 188, 357-366. [CrossRef]

22. Zhou, L.; Gao, D.; Zhao, J.; Wei, H.; Zhang, X.; Xu, Z.; Chen, R. Turbulent flame propagation with pressure oscillation in the end gas region of confined combustion chamber equipped with different perforated plates. Combust. Flame 2018, 191, 453-467. [CrossRef]

23. Borghi, R. On the structure and morphology of turbulent premixed flames. In Recent Advances in the Aerospace Science; Casci, C., Ed.; Plenum: New York, NY, USA, 1985; pp. 117-138. [CrossRef]

24. Li, J.; Liu, H.; Liu, X.; Ye, Y.; Yao, M. Development of a Simplified n-Heptane/Methane Model for the High-Pressure DirectInjection (HPDI) Natural Gas Marine Engines. Front. Energy 2021, 15, 405-420. [CrossRef]

25. Babajimopoulos, A.; Assanis, D.N.; Flowers, D.L.; Aceves, S.M.; Hessel, R.P. A Fully Coupled Computational Fluid Dynamics and Multi-Zone Model with Detailed Chemical Kinetics for the Simulation of Premixed Charge Compression Ignition Engines. Int. J. Engine Res. 2005, 6, 497-512. [CrossRef]

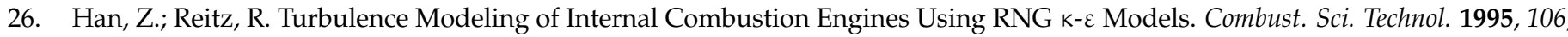
267-295. [CrossRef]

27. Senecal, P.; Richards, K.; Pomraning, E. A New Parallel Cut-Cell Cartesian CFD Code for Rapid Grid Generation Applied to In-Cylinder Diesel Engine Simulations. In Proceedings of the Sae World Congress, Detroit, MI, USA, $16-19$ April 2007. 
28. Senecal, P.; Pomraning, E.; Richards, K.; Briggs, T.; Choi, C.; Mcdavid, R.; Partterson, M. Multi-Dimensional Modeling of Direct-Injection Diesel Spray Liquid Length and Flame Lift-off Length using CFD and Parallel Detailed Chemistry. SAE Technol. 2003, 1. [CrossRef]

29. Gulder, O. Correlations of Laminar Combustion Data for Alternative, S.I. Engine Fuels. SAE Tech. Pap. 1984. [CrossRef]

30. Brownh, A.; Heywood, J. A Fundamentally-Based Stochastic Mixing Model Method for Predicting NO and Soot Emissions from Direct Injection Diesel Engines. Combust. Sci. Technol. 1988. [CrossRef]

31. Ewald, J.; Peter, N. A level set based flamelet model for the prediction of combustion in spark ignition engines. In Proceedings of the 15th International Multidimensional Engine Modeling User's Group Meeting, Detroit, MI, USA, 7 March 2004.

32. Senecal, K.; Pomraning, E.; Richards, K.J.; Som, S. An Investigation of Grid Convergence for Spray Simulations using an LES Turbulence Model. SAE Tech. Pap. 2013. [CrossRef]

33. Kim, J.; Riccardo, S.; Sibendu, S.; Ashish, S.; Munidhar, S.B.; Douglas, E.L. Numerical Investigation of a Fueled Pre-Chamber Spark-Ignition Natural Gas Engine. Int. J. Engine Res. 2021. [CrossRef]

34. Bai, X. Turbulent Combustion; Lund University: Lund, Sweden, 2008.

35. Loo, C.; Tame, N.; Penny, G. Effect of Iron Ores and Sintering Conditions on Flame Front Properties. ISIJ Int. 2012, 52, 967-976. [CrossRef]

36. Zhang, J.; Cheng, L.; Zheng, C.; Luo, Z.; Ni, M. Numerical Studies on the Inclined Flame Front Break of Filtration Combustion in Porous Media. Energy Fuels 2013, 27, 4969-4976. [CrossRef]

37. Xu, G.; Kotzagianni, M.; Kyrtatos, P.; Wright, Y.; Boulouchos, K. Experiental and numerical investigations of the unscavenged pre-chamber combustion in a rapid compression and expansion machine under engine-like conditions. Combust. Flame 2019, 204, 68-84. [CrossRef]

38. Liu, X.; Kokjohn, S.; Li, Y.; Wang, H.; Yao, M. A numerical investigation of the combustion kinetics of reactivity-controlled compression ignition (RCCI) combustion in an optical engine. Fuel 2019, 241, 753-766. [CrossRef]

39. Zheng, Z.; Fang, X.; Liu, H.; Yang, Z.; Yao, M. Study on the flame development patterns and flame speeds from homogeneous charge to stratified charge by fueling nheptane in an optical engine. Combust. Flame. 2019, 199, 213-229. [CrossRef]

40. Ye, Y.; Li, J.; Liu, H.; Wang, H.; Yao, M. A Numerical Investigation on Flame development and Emission Mechanism on a Natural-gas/Diesel Marine Engine. Trans. CSICE 2021, in press. 